\title{
Genetic variation within European tree species
}

\author{
G. MÜLLER-STARCK ${ }^{1,2}$, Ph. BARADAT ${ }^{3}$, and F. BERGMANN ${ }^{1}$ \\ 'Abteilung Forstgenetik und Forstpflanzenzüchtung, Universität Göttingen, Büsgenweg 2, \\ D-3400 Göttingen, Germany; ${ }^{2}$ Eidgenössische Forschungsanstalt für Wald, Schnee und \\ Landschaft, Zürcherstrasse 111, CH-8903 Birmensdorf, Switzerland; ${ }^{3}$ Institut National de la \\ Recherche Agronomique, Centre de Recherches de Bordeaux, Pierroton, F-33610 Cestas, \\ France
}

Received 7 December 1990; accepted 23 December 1991

Key words: genetic markers, isoenzymes, terpenes, polyphenols, heterozygosity, geographic differentiation

Application. Genetic variation is a fundamental requirement for the maintenance and longterm stability of forest ecosystems since amount and pattern of genetic variation determine the ability of forest tree species to adapt to the variability of environmental conditions.

\begin{abstract}
This paper reviews results of studies on genetic variation in various European coniferous and angiosperm tree species, with emphasis on Picea abies and Pinus sylvestris, Abies alba, Fagus sylvatica, and Castanea sativa. Most of the studies employ enzyme gene markers, but terpenes and other markers are also used. The comparison of data is complicated due to the variety of measures of genetic variation that are reported. Nevertheless, substantial differences in intra- and interpopulational genetic variation can be observed among and also within specics. Causes for such heterogeneity are briefly discussed. The necessity for monitoring genetic variation and for standardizing measurement of genetic variation is emphasized.
\end{abstract}

\section{Introduction}

During recent decades, forest ecosystems and forest resources in Central Europe have becn threatencd particularly by air pollution-induced environmental changes. These and other man-made deteriorating effects on forest ecosystems severely challenge the ability of the constituent forest tree populations to adapt to and to survive in spatially and temporally heterogeneous environmental conditions. This ability to adapt to change is a fundamental requirement for the maintenance of forest ecosystems. Within each tree species, the amount and pattern of genetic variation determine its adaptability and are consequently essential parameters of the long-term stability of forest ecosystems. 
The objective of this paper is to review the present state of knowledge on genetic variation within native European forest tree species and to point out causes of heterogeneity in intra- and interpopulational variation. We cite studies which aim at the utilization of biochemical markers, which are expressed environmentally independent. The majority of the studies employ enzyme gene markers detected by means of various electrophoretic methods. Low molecular weight substances such as terpenes and polyphenols are also considered. DNA restriction fragment length polymorphisms have not been applied to date to studies on intrapopulational genetic variation in European tree species.

In reviewing the publications on forest tree species, three major problems arise. Firstly, in many studies an appropriate genetic analysis is missing so that the genetic control and mode of inheritance of markers are not proven unequivocally. Secondly, methods of measuring genetic variation differ among studies, so that direct comparison of results is difficult. Thirdly, in many studies the gene and/or genotype frequencies are not communicated, so that the original data cannot be reanalysed and subjected to a direct comparison. Consequently, this review of genetic variation within European tree species can only describe major trends without detailed characterization and interpretation of differences in genetic structures within and among species.

\section{Brief survey of biochemical and molecular markers in use}

\section{(a) Terpenes and polyphenols}

Terpenes and polyphenols, as secondary metabolites, have a less obvious genetic control than isozymes and they are often used without precise information about their mode of inheritance. The first class of compounds is the more widely used, with the limitation that only coniferous forest species are concerned. They are generally extracted from cortex oleoresin. Improvement of gas-liquid chromatography (GLC) techniques with automatic integration of peak areas considerably enhances the number of hydrocarbons which can be separated and reduces the analytical cost. Polyphenols, which are found in both conifers and broadleaves have been investigated much less. Analytical techniques for monitoring polyphenols are paper chromatography, thin layer chromatography or high performance liquid chromatography (HPLC). 


\section{(b) Immunoproteins}

Immunological techniques can be efficiently used to study chemotaxonomic problems (for review see Prus-Głowacki 1982). Also clinal trends in immunoproteins ("antigenic" proteins) have been found among populations of Pinus sylvestris L. (Prus-Głowacki and Rudin 1981; Prus-Głowacki et al. 1985). Since the genetic control and the mode of inheritance of immunoproteins have not yet been elucidated, these substances are not suitable for monitoring genetic variation among individuals and populations, and will not be discussed further in this review.

\section{(c) Enzyme gene markers}

Isoenzymes quite frequently are found to be controlled by single gene loci, and thus, are very useful for monitoring genetic (allelic) variation. Certain enzyme systems often reveal considerable variation and are detectable in various plant tissues. Usually, alleles at isoenzyme loci are codominant. Occasional lack of isoenzyme banding as a consequence of "null alleles" is equivalent to recessive expression and results in underestimates of heterozygosity.

\section{(d) DNA markers}

Like enzyme gene markers, restriction fragment length polymorphisms (RFLP's) or other DNA variants allow for monitoring genetic polymorphisms in cases where appropriate genetic analyses have identified allelic variants (for specific problems in genetic analysis see Gillet 1990). The extremely high information potential will favour DNA markers in the future, although many techniques like "fingerprinting" reveal intrapopulational variation which does not necessarily correspond to allelic variation. To our knowledge, there are no results published to date on intra- or interpopulational genetic variation in European tree species using DNA markers. Chloroplast DNA, however, has been utilized to study phylogenetic relationships among species (e.g., Szmidt 1991) and for solving specific problems, like the classification of seedlots which originate from introgression zones (e.g., Szmidt et al. 1988).

\section{Results of experimental studies}

The present survey refers to forest tree species which are commonly considered as to be ecologically and/or economically important and are 
managed according to forestry, and not to agricultural regimes. Studies which mainly refer to characterization of components of mating systems are not included. Investigations involving only one population were taken into consideration only if no other information was available for that particular tree species. Studies using terpene markers, are reviewed separately from those which have used enzyme gene markers.

\section{Results of studies using terpenes or polyphenols}

\section{Biology and inheritance}

\section{Terpenes}

Monoterpenes ( $C_{10}$ hydrocarbons) and sesquiterpenes ( $C_{15}$ hydrocarbons) have been intensively studied in forest trees. Recent progress has been made in understanding their biosynthesis (Bernard-Dagan et al. 1982; Cori 1983) and the relationships between intensity of their synthesis and architecture of resin ducts (White and Nilsson 1984). Zavarin (1970) used correlations between expression of terpenes to help in understanding biochemical pathways. Squillace (1976) reviewed methods of evaluating the inheritance of these compounds and focused attention on autocorrelations between relative amounts. Birks and Kanowski (1988) consider that these autocorrelations are an important cause of error in determination of inheritance pattern of terpenic compounds and lead to uncertainty about the number of polymorphic loci involved in their biosynthesis. Strong genetic control of terpenes is well established by broad sense heritabilities close to 1 even when grafts are grown at different localities (Baradat and Yazdani 1988). Segregation data based on full-sib families support monogenic inheritance of terpenes in three European species: 3-carene in Norway spruce, Picea abies L. Karst. (Esteban et al. 1976); $\beta$-phellandrene, $\beta$-pinene, myrcene, limonene and 3-carene in Scots pine, Pinus sylvestris L. (Yazdani et al. 1982); 3-carene, myrcene, limonene, longifolene and caryophyllene in Maritime pine, Pinus pinaster Ait. (Baradat et al. 1972, 1974; Marpeau et al. 1975, 1983).

Pleiotropy of terpene genes is frequent due to common precursors in biosynthetic pathways. This is, for example, the case for 3-carene and terpinolene (Baradat et al. 1972). Linkage relationships have been reported in Maritime pine: genes which control 3-carene, myrcene and limonene belong to the same linkage group (Marpeau et al. 1983).

\section{Polyphenols}

Inheritance studies have been done on Norway spruce (Wellendorf and Kaufmann 1977) and on Scots pine (Thielges 1972; Yazdani and Lebreton 
1991). The last named authors found a case of pleiotropy, where one locus controlled two flavonoids, prodelphinidin and taxifolin.

\section{Use in the study of genetic variability}

Table 1 summarizes results on intraspecific variability in seven European species of conifers using terpenes or polyphenols. The main field of utilization of terpene and phenolic compounds is chemotaxonomy because they display a strong geographic variation. The corresponding data are usually relative concentrations which are mainly processed with classical statistical methods used for quantitative traits. The most widely spread biometrical technics are analysis of variance, discriminant analysis, and cluster analysis.

\section{Terpenes}

Many experimental results (see Table 1) suggest that terpene markers correspond to selection pressure in a similar way as isoenzymes can do. For instance, Li and Adams (1988) found in Douglas-fir (Pseudotsuga menziesii (Mirb.) Franco) a similar pattern of geographical variation using isozymes than v. Rudloff (1973) found for terpenoid compounds of needles (see also Baradat et al. 1991).

High discriminating power of terpenes at the population level may be a consequence of the fact that different molecular forms correspond to drastic changes of physiological properties of enzymes acting on metabolic pathways. The expected result is a very low effective mutation rate at loci which control terpenes. This property makes these markers useful also for phylogenetic studies (see Table 1).

As basic terpenoid data are quantitative, precise identification of genotypes is possible only when the dominance of a richness allele over a poorness allele, or vice-versa, is not great. Dominance relationships have been determined for $\beta$-pinene, 3-carene, myrcene, limonene, longifolene and caryophyllene in Maritime pine (Pinus pinaster). These relationships range from high dominance of the poorness allele for caryophyllene to moderate dominance of the richness allele for 3-carene (Bernard-Dagan and Baradat 1977; Baradat and Marpeau 1991b). Most authors describe natural variability for terpenes, without any previous genetic analysis, using percentages of each terpene from individual trees or from mean supplies (one GLC analysis of oleoresin representative of a stand, sampled from series of individuals). Only in a few cases have patterns of variation in terpenes been reported in terms of chemotypes (Gansel and Squillace 1976 for slash pine (Pinus elliottii Engelm.), Forrest 1979, 1980 for Scots pine), or gene frequencies (Baradat and Marpeau 1991b). 
Table 1. Survey of genetic variation in coniferous tree species on the basis of terpenes $(\mathrm{T})$ and polyphenols $(\mathrm{P})$

\begin{tabular}{lllllll}
\hline $\begin{array}{l}\text { Species } \\
\text { and } \\
\text { reference }\end{array}$ & $\begin{array}{l}\text { Sampling } \\
\text { design }\end{array}$ & Traits & $\begin{array}{l}\text { Levels } \\
\text { of variability }\end{array}$ & $\begin{array}{l}\text { Processing } \\
\text { of data }\end{array}$ & $\begin{array}{l}\text { Most } \\
\text { significant } \\
\text { compounds }\end{array}$ & $\begin{array}{l}\text { Genetic } \\
\text { conclusions }\end{array}$ \\
\hline
\end{tabular}

Abies alba Mill

Paule et al. 13 prov. T; QT Within and ANOVA Tricyclene, 50\% of variCzecho- prov. $\alpha$-pinene ance between slovakia

Moreau, $83 \mathrm{~F}_{0}, \quad \mathrm{~T}$; QT, Within $\quad \mathrm{F}_{\mathrm{s}}$ Pastuska $159 \mathrm{~F}_{1} \quad \mathrm{QL}$ stand 1991 trees

Abies cephalonica Loud.

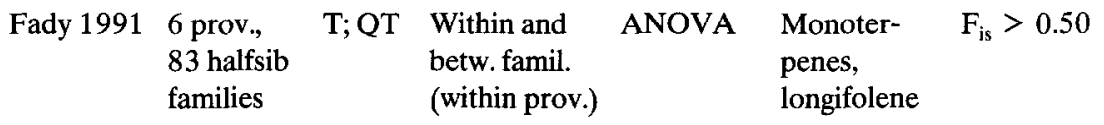

Cupressus sempervirens

$\begin{array}{lllllll}\begin{array}{l}\text { Schiller } \\ 1990\end{array} & \begin{array}{l}\text { 22 prov. } \\ \text { (Israel) }\end{array} & \text { T; QT } & \begin{array}{l}\text { Within and } \\ \text { between } \\ \text { prov. }\end{array} & \begin{array}{l}\text { Discr. } \\ \text { analysis, } \\ \text { cluster } \\ \text { analysis }\end{array} & \begin{array}{l}\text { Pinenes, } \\ \text { 3-carene, } \\ \text { phellan- } \\ \text { drene, } \\ \text { caryo- } \\ \text { phyllene }\end{array} & \begin{array}{l}\text { Israel prov. } \\ \text { belong to } \\ \text { different } \\ \text { origins }\end{array} \\ & & & & & \end{array}$

Pinus halepensis Mill.

$\begin{array}{lllllll}\begin{array}{l}\text { Schiller, } \\ \text { Grunwald } \\ 1987\end{array} & \begin{array}{l}\text { 22 prov. } \\ \text { (Europe, } \\ \text { Israel) }\end{array} & \text { T; QT } & \begin{array}{l}\text { Within and } \\ \text { between } \\ \text { prov. }\end{array} & \begin{array}{l}\text { Discr. } \\ \text { analysis, } \\ \text { cluster } \\ \text { analysis }\end{array} & \begin{array}{l}\alpha \text {-Pinene, } \\ \text { 3-carene, } \\ \text { myrcene }\end{array} & \begin{array}{l}\text { Structure } \\ \text { of geographic } \\ \text { variability }\end{array} \\ \begin{array}{l}\text { Baradat } \\ \text { et al. } 1989\end{array} & \begin{array}{l}4 \text { prov. } \\ \text { (Italy) }\end{array} & \text { T; QT } & \begin{array}{l}\text { Within and } \\ \text { between } \\ \text { prov. }\end{array} & \begin{array}{l}\text { Discr. } \\ \text { analysis, } \\ \text { cluster } \\ \text { analysis }\end{array} & \begin{array}{l}\text { 3-Carene, } \\ \alpha \text {-terpinene, } \\ \text { caryo- } \\ \text { phyllene }\end{array} & \begin{array}{l}\text { High discrimi- } \\ \text { of terpenes } \\ \text { between prov. }\end{array}\end{array}$

Pinus nigra Arnold

\begin{tabular}{|c|c|c|c|c|c|c|}
\hline $\begin{array}{l}\text { Arbez } \\
\text { et al. } 1974\end{array}$ & $\begin{array}{l}14 \text { prov. } \\
\text { (France, } \\
\text { Italy) }\end{array}$ & T; QT & $\begin{array}{l}\text { Between } \\
\text { subspecies } \\
\text { and geo- } \\
\text { graphic races }\end{array}$ & ANOVA & Limonene & $\begin{array}{l}\text { Discrimination } \\
\text { between } 4 \text { sub- } \\
\text { species and } \\
\text { between Laricio }\end{array}$ \\
\hline
\end{tabular}


Table 1. (Continued)

\begin{tabular}{lllllll}
\hline $\begin{array}{l}\text { Species } \\
\text { and } \\
\text { reference }\end{array}$ & $\begin{array}{l}\text { Sampling } \\
\text { design }\end{array}$ & Traits & $\begin{array}{l}\text { Levels } \\
\text { of variability }\end{array}$ & $\begin{array}{l}\text { Processing } \\
\text { of data }\end{array}$ & $\begin{array}{l}\text { Most } \\
\text { significant } \\
\text { compounds }\end{array}$ & $\begin{array}{l}\text { Genetic } \\
\text { conclusions }\end{array}$ \\
\hline $\begin{array}{l}\text { Fineschi, } \\
\text { Grossoni }\end{array}$ & $\begin{array}{l}2 \text { geo- } \\
\text { graphical } \\
\text { races }\end{array}$ & T; QT & $\begin{array}{l}\text { Between } \\
\text { geographi- } \\
\text { cal races }\end{array}$ & ANOVA & Limonene & $\begin{array}{l}\text { Discrimination } \\
\text { between Laricio } \\
\text { from Corsica } \\
\text { and Calabria }\end{array}$ \\
$\begin{array}{l}\text { Gerber } \\
\text { et al. 1991 }\end{array}$ & $\begin{array}{l}\text { 72 prov. } \\
\text { (southern } \\
\text { Europe) }\end{array}$ & T; QT & $\begin{array}{l}\text { Between } \\
\text { prov. and } \\
\text { subspecies }\end{array}$ & $\begin{array}{l}\text { Discr. } \\
\text { analysis, } \\
\text { cluster } \\
\text { analysis }\end{array}$ & $\begin{array}{l}\beta \text {-Pinene, } \\
\text { phellan- } \\
\text { drene, ca- } \\
\text { ryophyllene }\end{array}$ & $\begin{array}{l}\text { Revision } \\
\text { of taxonomy }\end{array}$ \\
\hline
\end{tabular}

Pinus pinaster Ait.

\begin{tabular}{|c|c|c|c|c|c|c|}
\hline $\begin{array}{l}\text { Baradat } \\
\text { et al. } 1979\end{array}$ & $\begin{array}{l}36 \text { prov. } \\
4 \text { geo- } \\
\text { graphical } \\
\text { groups }\end{array}$ & $\mathrm{T} ; \mathrm{QT}$ & $\begin{array}{l}\text { Within and } \\
\text { between } \\
\text { stands } \\
\text { and zones }\end{array}$ & $\begin{array}{l}\text { ANOVA } \\
\text { and } \\
\text { principal } \\
\text { component }\end{array}$ & $\begin{array}{l}\beta \text {-Pinene, } \\
\text { 3-carene, } \\
\text { caryo- } \\
\text { phyllene }\end{array}$ & $\begin{array}{l}\text { Structure of } \\
\text { geographic } \\
\text { variability; } \\
\text { panmictic } \\
\text { equilibrium }\end{array}$ \\
\hline $\begin{array}{l}\text { Baradat, } \\
\text { Marpeau } \\
\text { 1991a }\end{array}$ & $\begin{array}{l}105 \text { prov. } \\
\text { from na- } \\
\text { tural po- } \\
\text { pulations }\end{array}$ & $\mathrm{T} ; \mathrm{QL}$ & $\begin{array}{l}\text { Between } \\
\text { stands and } \\
\text { geographic } \\
\text { races }\end{array}$ & $\begin{array}{l}\text { Discr. } \\
\text { analysis, } \\
\text { cluster } \\
\text { analysis }\end{array}$ & $\begin{array}{l}\beta \text {-Pinene, } \\
3 \text {-carene, } \\
\text { caryo- } \\
\text { phyllene }\end{array}$ & $\begin{array}{l}\text { Reconstruction } \\
\text { of differences } \\
\text { among races }\end{array}$ \\
\hline $\begin{array}{l}\text { Baradat, } \\
\text { Marpeau } \\
1991 b\end{array}$ & $\begin{array}{l}105 \text { prov. } \\
\text { from na- } \\
\text { tural po- } \\
\text { pulations }\end{array}$ & $\mathrm{QL}$ & $\begin{array}{l}\text { Within } \\
\text { stands }\end{array}$ & $\begin{array}{l}\text { Test of } \\
\text { panmixia }\end{array}$ & 6 Terpenes & $\begin{array}{l}\text { Panmixia } \\
\text { except for } \\
\text { coastal stands }\end{array}$ \\
\hline $\begin{array}{l}\text { Baradat } \\
\text { et al. } 1991\end{array}$ & $\begin{array}{l}7 \text { geo- } \\
\text { graphical } \\
\text { races }\end{array}$ & $\begin{array}{l}\text { T; QT, } \\
\text { QL }\end{array}$ & $\begin{array}{l}\text { Between } \\
\text { geogr. races }\end{array}$ & $\begin{array}{l}\text { Discr. } \\
\text { analysis, } \\
\text { cluster } \\
\text { analysis }\end{array}$ & $\begin{array}{l}6 \text { Terpenes, } \\
17 \text { loci, } \\
312 \text { spots } \\
\text { total prot. }\end{array}$ & $\begin{array}{l}\text { Similar clus- } \\
\text { tering of races } \\
\text { with proteins } \\
\text { and terpenes }\end{array}$ \\
\hline $\begin{array}{l}\text { Idrissi- } \\
\text { Hassani, } \\
\text { Lebreton } \\
1992\end{array}$ & $\begin{array}{l}4 \text { geo- } \\
\text { graphical } \\
\text { races, } \\
80 \text { trees }\end{array}$ & $\begin{array}{l}\mathrm{T} ; \mathrm{QT} \\
\mathrm{QL}\end{array}$ & $\begin{array}{l}\text { Within and } \\
\text { between } \\
\text { gegraphi- } \\
\text { cal races }\end{array}$ & $\begin{array}{l}\text { Frequency } \\
\text { description }\end{array}$ & Kaempferol & $\begin{array}{l}\text { Discrimination } \\
\text { of races } \\
\text { from Morocco } \\
\text { and Landes }\end{array}$ \\
\hline \multicolumn{7}{|c|}{ Pinus sylvestris L. } \\
\hline $\begin{array}{l}\text { Tigerstedt, } \\
\text { Hiltunen } \\
1979\end{array}$ & $\begin{array}{l}146 \text { clones } \\
\text { from } \\
\mathrm{N}-\mathrm{S} \text { range }\end{array}$ & $\begin{array}{l}\text { T; QT, } \\
\text { QL }\end{array}$ & $\begin{array}{l}\text { Between } \\
\text { stands }\end{array}$ & Regression & 3-Carene & $\begin{array}{l}\text { Clinal } \\
\text { variation }\end{array}$ \\
\hline $\begin{array}{l}\text { Forrest } \\
1979\end{array}$ & $\begin{array}{l}17 \text { prov. } \\
\text { (Scotland) }\end{array}$ & $\mathrm{T} ; \mathrm{QL}$ & $\begin{array}{l}\text { Between } \\
\text { prov. }\end{array}$ & $\begin{array}{l}\text { Frequency } \\
\text { of terpe- } \\
\text { noid } \\
\text { patterns }\end{array}$ & $\begin{array}{l}\text { Pinenes, } \\
\text { myrcene, } \\
\text { phellandrene }\end{array}$ & $\begin{array}{l}\text { Large variability } \\
\text { between prov. }\end{array}$ \\
\hline
\end{tabular}


Table 1. (continued)

\begin{tabular}{|c|c|c|c|c|c|c|}
\hline $\begin{array}{l}\text { Species } \\
\text { and } \\
\text { reference }\end{array}$ & $\begin{array}{l}\text { Sampling } \\
\text { design }\end{array}$ & Traits & $\begin{array}{l}\text { Levels } \\
\text { of variability }\end{array}$ & $\begin{array}{l}\text { Processing } \\
\text { of data }\end{array}$ & $\begin{array}{l}\text { Most } \\
\text { significant } \\
\text { compounds }\end{array}$ & $\begin{array}{l}\text { Genetic } \\
\text { conclusions }\end{array}$ \\
\hline $\begin{array}{l}\text { Forrest } \\
1980\end{array}$ & $\begin{array}{l}41 \text { prov. } \\
\text { (Scotland) }\end{array}$ & $\mathrm{T} ; \mathrm{QL}$ & $\begin{array}{l}\text { Between } \\
\text { prov. }\end{array}$ & $\begin{array}{l}\text { Cluster } \\
\text { analysis }\end{array}$ & $\begin{array}{l}\text { Pinenes, } \\
\text { myrcene }\end{array}$ & $\begin{array}{l}\text { Clustering } \\
\text { of prov. into } \\
4 \text { main groups }\end{array}$ \\
\hline $\begin{array}{l}\text { Yazdani } \\
\text { et al. } 1985\end{array}$ & $\begin{array}{l}26 \text { prov. } \\
\text { (Sweden) }\end{array}$ & $\mathrm{T} ; \mathrm{QT}$ & $\begin{array}{l}\text { Between } \\
\text { prov. }\end{array}$ & $\begin{array}{l}\text { ANOVA } \\
\text { and discr. } \\
\text { analysis }\end{array}$ & $\begin{array}{l}\beta \text {-Pinene, } \\
\text { 3-carene, } \\
\text { limonene }\end{array}$ & $\begin{array}{l}\text { Clinal } \\
\text { variation }\end{array}$ \\
\hline $\begin{array}{l}\text { Yazdani, } \\
\text { Nilsson } \\
1986\end{array}$ & $\begin{array}{l}10 \text { prov. } \\
\text { (Sweden) }\end{array}$ & $\mathrm{T} ; \mathrm{QT}$ & $\begin{array}{l}\text { Within } \\
\text { and } \\
\text { between } \\
\text { prov. }\end{array}$ & $\begin{array}{l}\text { ANOVA } \\
\text { and discr. } \\
\text { analysis }\end{array}$ & $\begin{array}{l}\text { Limonene, } \\
\text { sabinene }\end{array}$ & $\begin{array}{l}\text { Clinal variation; } \\
85 \% \text { of variance } \\
\text { between prov. }\end{array}$ \\
\hline $\begin{array}{l}\text { Lebreton } \\
\text { et al. } 1990\end{array}$ & $\begin{array}{l}16 \text { geogra- } \\
\text { phical } \\
\text { zones } \\
\text { (Sweden, } \\
\text { France, } \\
\text { Spain); } \\
156 \text { indiv. }\end{array}$ & $\begin{array}{l}\mathrm{P} ; \mathrm{QT}, \\
\mathrm{QL}\end{array}$ & $\begin{array}{l}\text { Within } \\
\text { and } \\
\text { between } \\
\text { stands } \\
\text { and zones }\end{array}$ & $\begin{array}{l}\text { Regres- } \\
\text { sion and } \\
\text { frequency } \\
\text { analysis }\end{array}$ & $\begin{array}{l}\text { Prodel- } \\
\text { phinidin, } \\
\text { procya- } \\
\text { nidin, } \\
\text { quercetin }\end{array}$ & $\begin{array}{l}\text { High frequency } \\
\text { of chemotypes } \\
\text { with procya- } \\
\text { nidin and } \\
\text { quercetin in } \\
\text { low altitudes } \\
\text { populations }\end{array}$ \\
\hline
\end{tabular}

QT stands for "quantitative" and QL for "qualitative" traits, ANOVA for "analysis of variance", discr. for "discriminant", prov. for "provenance(s)", $F_{0}$ for parents and $F_{1}$ for descendants; $F_{\text {is }}$ designates the within population inbreeding coefficient (Wright 1969)

Studies on genetic variability involving terpenes generally use analyses of variance, multivariate analyses (principal components, discriminant analysis), and cluster analyses (see Table 1). They generally bear on comparison of provenances and geographic races and results can also partition the total variance between and within populations (e.g., Yazdani and Nilsson 1986 for Scots pine or Paule et al. 1987 for silver fir, Abies alba Mill.). Some studies estimate within stand inbreeding coefficients $\left(\mathrm{F}_{\mathrm{is}}\right.$, see Table 1).

\section{Polyphenols}

When HPLC analysis techniques are used, interpretation of genetic variability in phenolic compounds is similar to that employed for terpenes, i.e., the detection of genotypic classes underlying quantitative variation in concentrations. Although there are only a small number of studies and a few discriminating compounds, some flavonoids seem to have good taxonomic value for identifying geographic races. This is the case of 
kaempferol in Maritime pine (Idrissi-Hassani and Lebreton 1992) and for prodelphinidin, procyanidin and quercetin in Scots pine (Lebreton et al. 1991; see Table 1).

\section{Studies on intraspecific genetic variation using enzyme gene markers}

Studies utilizing enzyme gene markers quantify genetic variation at specified gene loci according to a variety of measures. There are varying concepts and overlapping definitions especially with respect to the terms differentiation, diversity and heterozygosity (Gregorius 1978, 1987; Müller-Starck and Gregorius 1986). When the term heterozygosity is used, most investigators mean actual (observed) heterozygosity, $\mathrm{H}_{\mathrm{a}}$, or expected heterozygosity, $\mathrm{H}_{\mathrm{e}}$ (Nei 1973), which is in reality a measure of genetic diversity. The conditional heterozygosity, $H_{c}$ (Gregorius et al. 1986), is independent of underlying allele frequencies, but is not yet in general use. Tables 2 and 3 briefly characterize degrees of intrapopulational variation by means of a compilation of the average numbers of alleles per locus, $A_{L}$, and the heterozygosities $H_{a}$ and $H_{e}$ respectively. The most frequently employed measure for interpopulational variation is $\mathrm{G}_{\mathrm{ST}}$ (Nei 1973), which is equivalent to $F_{\text {ST }}$ (Wright 1943, 1951). Recent studies also refer to the subpopulation differentiation, $\delta$ (Gregorius and Roberds 1986) which measures for each population its genetic distance from the remaining populations (lumped together). Additional comments in Tables 2 and 3 briefly summarize main conclusion from the respective studies.

The investigations summarized in Tables 2 and 3 reveal considerable variation among species and among studies within species in observed patterns of genetic diversity within and between populations. In the next section, an attempt is made to describe and classify possible causes for this heterogeneity of results.

\section{Causes for heterogeneity in intra- and interpopulational variation as inferred from enzyme gene markers}

Specific features of tree species

European forest tree species can be classified as follows:

(a) Species with large geographic ranges such as Picea abies, Pinus sylvestris or Fagus sylvatica tend to show little genetic differentiation among populations within regions, but greater differentiation among populations derived from different glacial refugia (continuous species). 
Table 2. Survey of genetic variation in European conifers based on isoenzymes

\begin{tabular}{llllllll}
\hline $\begin{array}{l}\text { Species } \\
\text { and }\end{array}$ & No. & Indiv. & No. & $A_{\mathrm{L}}$ & $\mathrm{H}$ & $\mathrm{G}_{\mathrm{ST}}$ & $\begin{array}{l}\text { Main conclusions about } \\
\text { intra- and/or }\end{array}$ \\
reference & of & per & of & $(\%)$ & $(\%)$ & $\begin{array}{l}\text { interpopulational } \\
\text { genetic variation }\end{array}$ \\
\hline
\end{tabular}

Abies alba Mill.

\begin{tabular}{|c|c|c|c|c|c|c|}
\hline $\begin{array}{l}\text { Bergmann and } \\
\text { Kownatzki } 1988\end{array}$ & $45^{(1)}$ & $25^{+}$ & 5 & 1.7 & & $\begin{array}{l}\text { Great allelic } \\
\text { differentiation among } \\
\text { pop. (Europe) }\end{array}$ \\
\hline $\begin{array}{l}\text { Bergmann et al. } \\
1990\end{array}$ & $45^{(1)}$ & $25^{+\#}$ & 10 & 1.8 & & $\begin{array}{l}\text { Variation in diversity } \\
\text { level and allelic } \\
\text { differentiation among } \\
\text { pop. (Europe) }\end{array}$ \\
\hline $\begin{array}{l}\text { Kormuták et al. } \\
1982\end{array}$ & 4 & $22^{*}$ & 9 & 3.3 & $56.3^{(\mathrm{a})}$ & $\begin{array}{l}\text { Great intrapop. } \\
\text { variation, small interpop. } \\
\text { differentiation (Slovakia) }\end{array}$ \\
\hline Kormuták 1988 & 7 & $29^{*}$ & 5 & & $43.1^{(\mathrm{a})}$ & $\begin{array}{l}\text { Great allelic variation } \\
\text { between two regions } \\
\text { (Slovakia) }\end{array}$ \\
\hline $\begin{array}{l}\text { Mejnartowicz } \\
1980\end{array}$ & 5 & $>25^{+}$ & 5 & 4.7 & $41.6^{(\mathrm{e})}$ & $\begin{array}{l}\text { Great intrapop., } \\
\text { moderate interpop. } \\
\text { differentiation (Poland) }\end{array}$ \\
\hline Schröder 1989 & 43 & $10-50^{+}$ & 4 & 2.2 & & $\begin{array}{l}\text { Distinct differentiation } \\
\text { among regions } \\
\text { (Germany) }\end{array}$ \\
\hline
\end{tabular}

Larix decidua Mill.

$\begin{array}{llllll}\text { Lewandowski and } & 11 & 100^{+} & 18 & 1.9 & 16.3^{(\mathrm{e})}\end{array}$

2.6 Relatively little differentiation among pop. (Poland)

Picea abies (L) Karst.

\begin{tabular}{|c|c|c|c|c|c|c|}
\hline Bergmann 1974 & 9 & $200^{+}$ & 4 & 2.7 & 4.0 & $\begin{array}{l}\text { Great differentiation } \\
\text { only between pop. in } \\
\text { Central Europe and } \\
\text { Scandinavia }\end{array}$ \\
\hline Bergmann 1975 & 15 & $200^{+}$ & 6 & 2.6 & & $\begin{array}{l}\text { Great differentiation } \\
\text { between northern, } \\
\text { central and southern } \\
\text { European pop. }\end{array}$ \\
\hline $\begin{array}{l}\text { Bergmann and } \\
\text { Gregorius } 1979\end{array}$ & 21 & $200^{+}$ & 7 & 2.6 & $41.1^{(\mathrm{e})}$ & $\begin{array}{l}\text { Differences in intrapop. } \\
\text { variat. between marginal } \\
\text { and central pop. } \\
\text { (Europe) }\end{array}$ \\
\hline
\end{tabular}


Table 2. (Continued)

\begin{tabular}{|c|c|c|c|c|c|c|c|}
\hline $\begin{array}{l}\text { Species } \\
\text { and } \\
\text { reference }\end{array}$ & $\begin{array}{l}\text { No. } \\
\text { of } \\
\text { pop. }\end{array}$ & $\begin{array}{l}\text { Indiv. } \\
\text { per } \\
\text { pop. }\end{array}$ & $\begin{array}{l}\text { No. } \\
\text { of } \\
\text { loci }\end{array}$ & $A_{L}$ & $\begin{array}{l}\mathrm{H} \\
(\%)\end{array}$ & $\begin{array}{l}\mathrm{G}_{\mathrm{ST}} \\
(\%)\end{array}$ & $\begin{array}{l}\text { Main conclusions about } \\
\text { intra- and/or } \\
\text { interpopulational } \\
\text { genetic variation }\end{array}$ \\
\hline Bergmann 1983 & 38 & $200^{-1}$ & 3 & & & & $\begin{array}{l}\text { Distinct differentiation } \\
\text { between pop. based on } \\
\text { private alleles (Central } \\
\text { Europe and Scandinavia) }\end{array}$ \\
\hline $\begin{array}{l}\text { Giannini et al. } \\
1991\end{array}$ & 9 & $150^{+}$ & 21 & 1.8 & $16.5^{(\mathrm{e})}$ & 4.2 & $\begin{array}{l}\text { Minor polymorphism; } \\
\text { small interpop. variation } \\
\text { (north. Italy) }\end{array}$ \\
\hline $\begin{array}{l}\text { Konnert and } \\
\text { Franke } 1990\end{array}$ & 39 & $12-45^{*}$ & 11 & 2.2 & & & $\begin{array}{l}\text { Interpop. variation } \\
\text { between indigenous and } \\
\text { artifical pop. (South. } \\
\text { Germany) }\end{array}$ \\
\hline $\begin{array}{l}\text { Lagercrantz } \\
\text { and Ryman } 1990\end{array}$ & 70 & $28-51^{\#}$ & 22 & 1.6 & $11.5^{(a)}$ & 5.2 & $\begin{array}{l}\text { Rel. great intra- and rel. } \\
\text { small interpop. variation; } \\
\text { diversity differences } \\
\text { between pop. (Northeast. } \\
\text { and Central Europe) }\end{array}$ \\
\hline $\begin{array}{l}\text { Lundkvist and } \\
\text { Rudin } 1977\end{array}$ & 11 & $35-80^{*}$ & 4 & 4.3 & $35.8^{(\mathrm{e})}$ & 2.0 & $\begin{array}{l}\text { Small interpopul. } \\
\text { variation among } \\
\text { populations (Sweden) }\end{array}$ \\
\hline Lundkvist 1979 & 4 & $49-64^{*}$ & 11 & 3.8 & $36.0^{(\mathrm{a})}$ & 3.0 & $\begin{array}{l}\text { Small interpopul. } \\
\text { variation among } \\
\text { populations (Sweden) }\end{array}$ \\
\hline Muona et al. 1990 & 2 & $23^{*}$ & 14 & 2.7 & $20.0^{(\mathrm{e})}$ & 12.0 & $\begin{array}{l}\text { Rel. great intrapop. } \\
\text { variation and clear } \\
\text { differentiation between } \\
\text { pop. (Finland, Slovakia) }\end{array}$ \\
\hline Stutz 1990 & 19 & $40^{*}$ & 6 & & & 2.5 & $\begin{array}{l}\text { Certain differentiation } \\
\text { among pop. }\end{array}$ \\
\hline Tigerstedt 1973 & 2 & $45^{*}$ & 4 & 2.5 & $43.0^{(a)}$ & & $\begin{array}{l}\text { Rel. great intrapop. } \\
\text { variation in marginal and } \\
\text { central pop. (Finland) }\end{array}$ \\
\hline Tigerstedt 1979 & 10 & $18-107^{*}$ & 6 & & & 5.0 & $\begin{array}{l}\text { No differences in } \\
\text { intrapop. variation } \\
\text { among pop.; higher } \\
\text { homozygosity at the } \\
\text { species margin }\end{array}$ \\
\hline \multicolumn{8}{|l|}{ Pinus cembra $\mathrm{L}$. } \\
\hline $\begin{array}{l}\text { Krutovskii and } \\
\text { Politov 19912) }\end{array}$ & 1 & $16^{*}$ & 19 & 1.5 & $\begin{array}{l}12.8^{(\mathrm{a})} \\
10.9^{(\mathrm{e})}\end{array}$ & & $\begin{array}{l}\text { Very small intrapop. } \\
\text { variation (Siberia) }\end{array}$ \\
\hline
\end{tabular}


Table 2. (Continued)

\begin{tabular}{|c|c|c|c|c|c|c|c|}
\hline $\begin{array}{l}\text { Species } \\
\text { and } \\
\text { reference }\end{array}$ & $\begin{array}{l}\text { No. } \\
\text { of } \\
\text { pop. }\end{array}$ & $\begin{array}{l}\text { Indiv. } \\
\text { per } \\
\text { pop. }\end{array}$ & $\begin{array}{l}\text { No. } \\
\text { of } \\
\text { loci }\end{array}$ & $\mathbf{A}_{\mathrm{L}}$ & $\begin{array}{l}\mathrm{H} \\
(\%)\end{array}$ & $\begin{array}{l}\mathrm{G}_{\mathrm{ST}} \\
(\%)\end{array}$ & $\begin{array}{l}\text { Main conclusions about } \\
\text { intra- and/or } \\
\text { interpopulational } \\
\text { genetic variation }\end{array}$ \\
\hline
\end{tabular}

\begin{tabular}{|c|c|c|c|c|c|c|c|}
\hline Szmidt 1982 & 11 & $22.5^{*}$ & 8 & 1.9 & $26.0^{(\mathrm{c})}$ & $32.0^{3)}$ & $\begin{array}{l}\text { Very large interpop. } \\
\text { variation among } \\
\text { European pop. }\end{array}$ \\
\hline
\end{tabular}

Pinus halepensis Mill.

$\begin{array}{lllllllll}\text { Loukas et al. 1983 } & 3 & 16-83^{*} & 10 & 2.1 & 17.1^{(\mathrm{e})} & 1.3 & \begin{array}{l}\text { Great intrapop. variation } \\ \text { and very small interpop. } \\ \text { variation }\end{array} \\ \text { Schiller et al. } 1986 & 19 & 75^{+} & 30 & 1.2 & 4.0^{(\mathrm{e})} & \begin{array}{l}\text { Small intrapop. variation; } \\ \text { greater differentiation } \\ \text { between two races }\end{array}\end{array}$

Pinus leucodermis Ait.

$\begin{array}{llrrrr}\text { Morgante and } & 5 & 23^{*} & 23 & 1.6 & 12.4^{(\mathrm{e})} \\ \text { Vendramin 1990 } & 2 & 145^{+} & 23 & 1.4 & 11.0^{(\mathrm{e})}\end{array}$

4.0 Little intra- and interpop. variation (Italy (5), Greece (2))

Pinus nigra Arnold

\begin{tabular}{|c|c|c|c|c|c|c|c|}
\hline $\begin{array}{l}\text { Bonnet-Masimbert } \\
\text { and Bikay-Bikay } 1978\end{array}$ & 40 & $125^{+}$ & 4 & 2.4 & & 9.8 & $\begin{array}{l}\text { Differentiation among } \\
\text { the five subspec. in } \\
\text { mediterranean area }\end{array}$ \\
\hline Fineschi 1984 & 11 & $64^{+}$ & 2 & 2.5 & & & $\begin{array}{l}\text { Great differentiation } \\
\text { among geographical } \\
\text { groups of pop. (Italy) }\end{array}$ \\
\hline $\begin{array}{l}\text { Nikolić and 'Tucić } \\
1983\end{array}$ & 28 & $14-72^{+*}$ & 4 & 3.0 & $27.2^{(\mathrm{e})}$ & 13.5 & $\begin{array}{l}\text { Great intra- and rel. } \\
\text { small interpop. variation; } \\
\text { differentiation between } \\
\text { subspecies }\end{array}$ \\
\hline
\end{tabular}

Pinus pumila (Pall.) Regel

$\begin{array}{lllllll}\text { Krutovskii and } & 3 & 56^{*} & 17 & 2.3 & 24.7^{(\text {(a) }} \\ \text { Politov 19912) } & & & & & 24.8^{(\mathrm{e})}\end{array}$

Rel. large intra- and interpop. variation (Siberia)

Pinus sibirica Du Tour

$\begin{array}{llllllll}\begin{array}{l}\text { Krutovskii et al. } \\ 1989\end{array} & 9 & 37^{*} & 14 & 1.6 & 16.3^{(\mathrm{a})} & 1.6 & \begin{array}{l}\text { Little interpop. } \\ \text { variation (Eastern } \\ \text { Siberia) }\end{array}\end{array}$


Table 2. (Continued)

\begin{tabular}{llllllll}
\hline $\begin{array}{l}\text { Species } \\
\text { and }\end{array}$ & No. & Indiv. & No. & $A_{\mathrm{L}}$ & $\mathbf{H}$ & $\mathrm{G}_{\mathrm{ST}}$ & $\begin{array}{l}\text { Main conclusions about } \\
\text { intra- and/or } \\
\text { reference }\end{array}$ \\
of & per & of & $(\%)$ & $(\%)$ & $\begin{array}{l}\text { interpopulational } \\
\text { genetic variation }\end{array}$ \\
\hline
\end{tabular}

Pinus sylvestris L.

\begin{tabular}{|c|c|c|c|c|c|c|c|}
\hline Gullberg et al. 1982 & 3 & $45^{*}$ & 9 & 2.9 & $\begin{array}{l}29.7^{(\mathrm{a})} \\
30.3^{(\mathrm{c})}\end{array}$ & 1,0 & $\begin{array}{l}\text { Moderate genetic } \\
\text { variation among } \\
\text { adjacent pop. }\end{array}$ \\
\hline Gullberg et al. 1985 & 9 & $60^{*}$ & 11 & 2.9 & & 2.0 & $\begin{array}{l}\text { Great intra- and } \\
\text { little interpop. } \\
\text { variation (Sweden) }\end{array}$ \\
\hline Krzakowa $1982^{4}$ ) & 8 & $32 *$ & 6 & & & & $\begin{array}{l}\text { Differentiation } \\
\text { between north. and } \\
\text { south. pop. (Poland) }\end{array}$ \\
\hline Mejnartowicz 1979 & 19 & $30^{*}$ & 3 & 3.9 & $38.6^{(2)}$ & $16.0^{3)}$ & $\begin{array}{l}\text { Very large intra- and } \\
\text { interpop. variation } \\
\text { (Poland) }\end{array}$ \\
\hline $\begin{array}{l}\text { Mejnartowicz and } \\
\text { Bergmann } 1985\end{array}$ & 9 & $17.5^{*}$ & 9 & 2.6 & $33.5^{(\mathrm{e})}$ & & $\begin{array}{l}\text { Great intra- and little } \\
\text { interpop. variation } \\
\text { (Poland) }\end{array}$ \\
\hline $\begin{array}{l}\text { Mejnartowicz and } \\
\text { Palowski (1989) }\end{array}$ & 6 & $25^{*}$ & 8 & 3.3 & $\begin{array}{l}30.7^{(\mathrm{a})} \\
37.5^{(\mathrm{e})}\end{array}$ & 7.6 & $\begin{array}{l}\text { Great intra- and rel. } \\
\text { little interpop. } \\
\text { variation (Poland) }\end{array}$ \\
\hline $\begin{array}{l}\text { Müller-Starck } 1987 \text {, } \\
\text { Müller-Starck and } \\
\text { Gregorius } 1986\end{array}$ & 9 & $120^{*}$ & 10 & 3.1 & $26.8^{(2)}$ & 2.0 & $\begin{array}{l}\text { Great intra- and little } \\
\text { interpop. variation } \\
\text { (Bavaria) }\end{array}$ \\
\hline $\begin{array}{l}\text { Muona and Szmidt } \\
1985\end{array}$ & 3 & $133^{*}$ & 14 & 3.0 & $25-30^{(e)}$ & 0.6 & $\begin{array}{l}\text { Little interpop. variation } \\
\text { (Northern Sweden) }\end{array}$ \\
\hline $\begin{array}{l}\text { Prus-Glowacki } \\
\text { (pers. comm.) }\end{array}$ & 17 & $30^{*}$ & 8 & 2.8 & $35.9^{(a)}$ & & $\begin{array}{l}\text { Great intra- and } \\
\text { interpop. variation } \\
\text { (European habitat) }\end{array}$ \\
\hline Rudin et al. 1974 & 3 & $207^{*}$ & 3 & 4.3 & & $3.0^{3 \mathrm{j}}$ & $\begin{array}{l}\text { Great intra- and little } \\
\text { interpop. variation } \\
\text { (Sweden) }\end{array}$ \\
\hline
\end{tabular}

\footnotetext{
+ Seed lot (macrogametophyte)

1) Populations in common

* Seed lot (embryo)

2) See also Krutovskii et al. 1990

* Adult trees

3) Loc. cit. Gullberg et al. 1985

4) See also Krzakowa and Szweykowski (1979)
}

$\mathrm{A}_{\mathrm{L}}$ stands for "average number of alleles per locus", $\mathrm{H}$ for "average heterozygosity per population" (index (a) indicates "actual", index (e) "expected "heterozygosity), $\mathbf{G}_{\mathrm{ST}}$ for "proportion of total diversity among populations", and pop. for "population(s)" (see text for further explanation). 
Table 3. Survey of genetic variation in European angiosperm tree species based on isoenzymes

\begin{tabular}{llllllll}
\hline $\begin{array}{l}\text { Species } \\
\text { and }\end{array}$ & No. & Indiv. & No. & $A_{\mathrm{L}}$ & $\mathrm{H}$ & $\mathrm{G}_{\mathrm{ST}}$ & $\begin{array}{l}\text { Main conclusion } \\
\text { about intra- and/or } \\
\text { reference }\end{array}$ \\
of & per & of & $(\%)$ & $(\%)$ & $\begin{array}{l}\text { interpopulational } \\
\text { genetic variation }\end{array}$ \\
\hline
\end{tabular}

\section{Castanea sativa Mill.}

Fineschi et al. $1990 \quad 13 \quad 101^{*} \quad 8 \quad 2.1$

Differentiation between north. and south. pop.

(Italy)

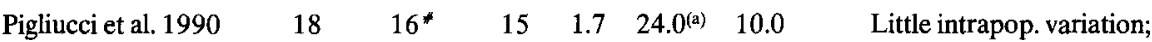
clinal variation suggested (Italy)

$\begin{array}{llllllll}\text { Villani et al. 1991a } & 15 & 25^{*} & 13 & 1.6 & 21.0^{(\mathrm{e})} & 8.7 & \text { Rel.great interpop }\end{array}$ variation; no geographical trends (Italy)

$\begin{array}{lllllll}\text { Villani et al. 1991b } & 13 & 2^{*} & 16 & 2.3 & 27.2^{\text {(a) }} & 16.7\end{array}$

Clear differentiation between eastern and west. pop. (Turkey)

Fagus sylvatica L.

\begin{tabular}{|c|c|c|c|c|c|c|c|}
\hline $\begin{array}{l}\text { Barrière et al. } \\
1984^{2)}\end{array}$ & $210^{1)}$ & $50^{*}$ & 3 & 2.3 & & & $\begin{array}{l}\text { Differentiation among } \\
\text { geographical groups of } \\
\text { pop. (Europe) }\end{array}$ \\
\hline $\begin{array}{l}\text { Comps et al. } \\
1987\end{array}$ & $104^{1)}$ & $50^{*}$ & 4 & 2.2 & & & $\begin{array}{l}\text { Differentiation through } \\
\text { the Atlantic range }\end{array}$ \\
\hline $\begin{array}{l}\text { Comps et al. } \\
1990\end{array}$ & $140^{1)}$ & $50^{*}$ & 6 & 2.3 & $28.9^{\text {(a) }}$ & 5.4 & $\begin{array}{l}\text { Differentiation between } \\
\text { continental and } \\
\text { Mediterr. regions }\end{array}$ \\
\hline $\begin{array}{l}\text { Comps et al. } \\
1991\end{array}$ & $35^{1)}$ & $50^{*}$ & 6 & 2.2 & & $3.6-5.2$ & $\begin{array}{l}\text { Differentiation between } \\
\text { low- and highland pop. } \\
\text { (Croatia) }\end{array}$ \\
\hline $\begin{array}{l}\text { Felber and } \\
\text { Thiebaut } 1984\end{array}$ & $41^{1)}$ & $50^{*}$ & 2 & 2.5 & & & $\begin{array}{l}\text { Differentiation among } \\
\text { geographical groups of } \\
\text { pop. (Central Europe) }\end{array}$ \\
\hline $\operatorname{Kim} 1980,1985$ & 2 & $596^{*}$ & 1 & 4.0 & $31.2^{\text {(a) }}$ & & $\begin{array}{l}\text { Great intra- and } \\
\text { interpop. variation } \\
\text { (Germany, Rumania) }\end{array}$ \\
\hline $\begin{array}{l}\text { Merzeau et al. } \\
1989\end{array}$ & 2 & $12.5^{* 3)}$ & $\begin{array}{c}4 \\
(2)\end{array}$ & 2.3 & & & $\begin{array}{l}\text { Great intrapop. variation } \\
\text { in pollen (South. France) }\end{array}$ \\
\hline $\begin{array}{l}\text { Müller-Starck } \\
1985,1989\end{array}$ & 6 & $96 *$ & 16 & 2.6 & $25.1^{(\mathrm{a})}$ & & $\begin{array}{l}\text { Great intrapop. variation } \\
\text { (Germany) }\end{array}$ \\
\hline
\end{tabular}


Table 3. (Continued)

\begin{tabular}{llllllll}
\hline $\begin{array}{l}\text { Species } \\
\text { and } \\
\text { reference }\end{array}$ & $\begin{array}{l}\text { No. } \\
\text { of } \\
\text { pop. }\end{array}$ & $\begin{array}{l}\text { Indiv. } \\
\text { per } \\
\text { pop. }\end{array}$ & $\begin{array}{l}\text { No. } \\
\text { of } \\
\text { loci }\end{array}$ & $\begin{array}{l}\mathrm{A} \\
(\%)\end{array}$ & $\begin{array}{l}\mathrm{G}_{\mathrm{ST}} \\
(\%)\end{array}$ & $\begin{array}{l}\text { Main conclusion } \\
\text { about intra- and/or } \\
\text { interpopulational } \\
\text { genetic variation }\end{array}$ \\
$\begin{array}{l}\text { Müller-Starck } \\
\text { and Ziehe 1991 }\end{array}$ & 5 & $172^{*}$ & 13 & 2.7 & $22.2^{(\text {a) }}$ & $\begin{array}{l}1.6 \\
4.5^{4)}\end{array}$ & $\begin{array}{l}\text { Great intra- and small } \\
\text { interpop. variation } \\
\text { (Germany) }\end{array}$ \\
$\begin{array}{llllll}\text { Thiebaut et al. 1982 } \\
\text { Intrapop. variation }\end{array}$ \\
\end{tabular}

Ficus carica

Valizadeh 1977

$\begin{array}{llll}4 & 90^{*} & 2 & 2.7\end{array}$

Deficiency of heterozygotes, small variation (South. France)

Quercus ilex L.

Lumaret et al. $\begin{array}{llll}37 & 35^{*} & 3 & 2.8\end{array}$

7.3

Differentiation among North African and 1991 South. European pop.

Quercus petraea Liebl.

$\begin{array}{lccccccl}\begin{array}{l}\text { Zanetto and } \\ \text { Kremer 1991 }\end{array} & 32 & 120^{*} & 15 & 3.2 & 27.5^{(\mathrm{e})} & 1.7 & \begin{array}{l}\text { Large intrapop. and } \\ \text { small interpop. variation } \\ \text { (West. Europe) }\end{array} \\ \begin{array}{l}\text { Müller-Starck } \\ \text { and Ziehe 1991 }\end{array} & 5 & 155^{+} & 13 & 3.1 & 21.9^{(\text {a) }} & 3.6 & \begin{array}{l}\text { Large intrapop. and } \\ \text { moderate interpop. } \\ \text { variation (Germany) }\end{array}\end{array}$

Quercus robur $\mathrm{L}$.

Müller-Starck and Ziehe 1991

$\begin{array}{llllll}5 & 166^{+} & 13 & 3.2 & 21.3^{(\mathrm{a})} & 1.8 \\ & & & & & 5.5^{4)}\end{array}$
Large intrapop. and small interpop. variation (Germany)

\footnotetext{
* Seeds

1) Partially populations in common

+ 2-year old plants

2) See also Cuguen et al. 1985, 1988

* Adult trees

3) Pollen contribution to seed lots from single trees

4) Subpop. differcntiation $\delta$ (Gregorius and Roberds 1986)
}

$A_{L}$ stands for "average number of alleles per locus", $H$ for "average heterozygosity per population" (index (a) indicates "actual", index (e) "expected "heterozygosity), $G_{S T}$ for "proportion of total diversity among populations", and pop. for "population(s)" (see text for further explanation) 
(b) Species with large geographic ranges, but subdivided into different subspecies (races) such as Pinus nigra, Pinus halepensis or Larix decidua, reveal little interpopulational variation within subspecies, but great differentiation among subspecies (disjunct species).

(c) Species with small and geographically disjunct ranges like Abies alba or Pinus cembra tend to show a great interpopulational differentiation and moderate intrapopulational genctic variation (cndemic species).

(d) Species with extremely small geographic ranges like Pinus pumila reveal relatively great interpopulational differentiation (relic species). Further studies may help to find out why this does not seem to hold for another species of this type, P. leucodermis.

\section{Heterogeneity of population types and environments}

Various types of populations may be sampled, mostly indigenous ones, but within the same species introduced populations or mixtures of both may also be sampled. Populations may differ in amounts of genetic variation because some may have gone through historical bottlenecks in population sizes, others not. It cannot be excluded that different silvicultural management affect the genetic structures of the respective populations. It is selfevident that environmental conditions can differ substantially even within small areas. The great natural micro- and macro-habitat variation always will complicate standardization of genetic inventories.

Furthermore, intra-specific heterogeneity in genetic variation within populations can be a consequence of sampling at different census stages, biased sampling, or small sample sizes. Due to varying reproduction, effective neighborhood sizes, fertility and/or viability selection (e.g. against inbreds), sampling at the seed stage or subsequent stages may not be representative of the genetic structure in the parental population. Even within the same age class, sampling of only flowering trees will not necessarily represent the entire population. As can be seen from Tables 2 and 3 , sample sizes varied considerably among the studies. This is true for the number of investigated populations per region, as well as the number of individuals per population.

\section{Methodical pitfalls}

\section{(a) Choice of enzyme systems}

Heterogeneity in isoenzyme data for the same tree species can result when the numbers and types of enzyme gene loci differ among studies. In the early days of isoenzyme surveys in tree species, enzyme systems such as 
peroxidases, esterases, phosphatases and aminopeptidases were studied, which later turned out to be very polymorphic. Hence, the respective estimates of the variation measures were relatively high compared to later studies, in which many other - partly invariant - enzyme systems, such as aminotransferases, dehydrogenases and isomerases, were included.

\section{(b) Different interpretations of genetic control of isoenzymes}

Differences in diversity estimates among studies can also occur if the number of loci controlling an enzyme is interpreted differently by different investigators of the same tree species. For example, the GOT system in Scots pine is assumed to be encoded by two, three or five gene loci depending on the results of different research groups (see Szmidt 1980). Estimates of the genetic diversity are likely to be much greater if isoenzymes, actually under the control of multiple loci, are assumed to be controlled by a single locus. Therefore it is always necessary to identify the correct number of gene loci underlaying enzyme polymorphisms prior to estimating genetic variability in populations. This includes a check on possible ontogenetic and/or environmental instabilities in the expression of enzyme systems on zymograms (e.g., Bergmann et al. 1989).

\section{(c) Inclusion of monomorphic gene loci}

Some investigators include monomorphic loci in their estimates of genetic variation while others do not. In one case, these estimates will be biased upwards, the other, downwards. The problem is that many investigators do not communicate whether or not monomorphic loci were excluded.

If the extent of intra- and interpopulational genetic variation should be compared in studies on geographical variation, it is not advisable to include monomorphic enzyme loci in samples of enzyme loci: patterns of variation will be the same, but the absolute magnitude of differences will be less when all loci are included. In particular, the "averaging effect" in the calculation of measures of genetic distance and $F_{\mathrm{ST}}$ or $G_{\mathrm{ST}}$ values would bias the extent of differentiation, if the proportion of monomorphic loci among the loci used in the study is relatively high.

\section{Concluding remarks}

In spite of the great variety of environmental conditions and forest stand characteristics in different studies, general tendencies are observed in 
genetic patterns of geographic variation related to species distribution, i.e., continuous, disjunct, endemic, and relic.

Methodological problems are evident which concern the choice of population and of samples per population, the choice of enzyme systems and loci, the methods used to quantify genetic variation, and in several cases also the verification of the genetic control and inheritance of markers. Generally, it appears that the quantification of interpopulational genetic variation suffers from a lack of appropriate measures: The widely applied $F_{\mathrm{ST}}$ or $G_{\mathrm{ST}}$ values represent in reality fixation indices which therefore cannot be considered as the most favourable condition for the measurement of genetic differentiation among populations. Furthermore, the partition of a total genetic variation into an intra- and interpopulational additive component appears as a concept which needs to be extended or restated in order to improve the accuracy of measures of genetic variation among populations (for suggestions see Gregorius 1988).

Although there is an increase in forest genetics research in Europe, the majority of published results still refer to coniferous and not to angiosperm tree species. While there is increasing work on Fagus sylvatica, there are no studies on Acer, Fraxinus, Tilia, or Ulmus species. The choice of which forest tree species to study seems to depend primarily on their economic importance, and not on their ecological significance. Studies on ecologically important species are especially needed in Central Europe, where forest tree populations are severely threatened by airpollution.

It appears that ecological genetic research in forestry has to be intensified in nearly all European countries. Moreover, present and future information on genetic variation in European tree species needs to be incorporated into strategies for the preservation of genetic resources so that adaptability of forest tree populations to changing environments can be maintained.

\section{Acknowledgments}

We are grateful to many colleagues who provided reprints and in some cases also unpublished data. At the same time we apologize that not all contributions could be cited in this review. We greatly appreciate the help of H. Glock, M. Günther, and A. Uteau in the preparation of the manuscript. Finally, we wish to thank unknown referees for very helpful comments and suggestions. 


\section{References}

Arbez, M., Bernard-Dagan, C. and Fillon, C. 1974. Variabilité intraspécifique des monoterpènes de Pinus nigra. Bilan des premiers resultats. Ann. Sci. For. 31(1): 57-70.

Baradat, Ph., Bernard-Dagan, C., Fillon, C. and Marpeau, A. 1972. Les terpènes du Pin maritime: aspects biologiques et génétiques. 2. Hérédité de la teneur en monoterpènes. Ann. Sci. For. 29(3): 507-334.

Baradat, Ph., Bernard-Dagan, C. and Pauly, G. 1974. Les terpènes du Pin maritime: aspects biologiques et génétiques. 3. Hérédité de la teneur en myrcène. Ann. Sci. For. 32(1): $29-54$

Baradat, Ph., Bernard-Dagan, C. and Marpeau, A. 1979. Variation of terpenes within and between populations of Maritime pine, pp. 151-168. In: Rudin, D. (Ed) Proceedings of the IUFRO Conference on Biochemical Genetics of Forest Trees, Umea, Sweden, 1978.

Baradat, Ph. and Yazdani, R. 1988. Stability of genotypic expression for monoterpene synthesis in clones of Scots pine growing in different sites. Scand. J. Forest Res. 3: 2536.

Baradat, Ph. and Marpeau, A. 1991 a. Reconstitution of differentiation of Maritime pine on the basis of terpenic data. (submitted to Ann. Sci. For.)

Baradat, $\mathrm{Ph}$. and Marpeau, A. 1991 b. Genetic structure of natural stands of Maritime pine on the basis of terpenic data. (submitted to Ann. Sci. For.).

Baradat, Ph., Lambardi, M. and Michelozzi, M. 1989. Terpene composition for four Italian provenances of Aleppo pine. J. Genet. Breeding 43:195-200.

Baradat, Ph., Barhman, N. and Petit, R. 1991. Comparison of relationships between geographical races of Maritime pine based on three kinds of gene markers: terpenes, isozymes and total proteins. (submitted to Theor. Appl. Genetics).

Barrière, G., Comps, B., Cuguen, J., N'Tsiba, F. and Thiebaut, B. 1984. The genetical ecological variability of beech (Fagus sylvatica L.) in Europe - an alloenzymatic study: genetic isolations of beechwoods, pp. 24-50. In: Proceedings of the First Symposium on Improvement and Silviculture of Beech, Grosshansdorf 1984, IUFRO Project Group P1 $10-00$

Bergmann, F. 1974. Genetischer Abstand zwischen Populationen. II. Die Bestimmung des genetischen Abstands zwischen europäischen Fichtenpopulationen (Picea abies) auf der Basis von Isoenzym-Genhäufigkeiten. Silvae Genetica 23: 28-32.

Bergmann, F. 1975. Herkunfts-Identifizierung von Forstsaatgut auf der Basis von IsoenzymGenhäufigkeiten. All. Forst- u. Jagdzeitung 146(10): 191-195.

Bergmann, F. 1983. Ein besonderer Fall geographischer Variation an zwei Enzym-Genloci der Fichte (Picea abies), pp. 8-24. In: Verhandlungen 3. Arbeitstagung: FORUM Genetik-Wald-Forstwirtschaft. Universität Göttingen.

Bergmann, F. and Gregorius, H.-R. 1979. Comparison of the genetic diversities of various populations of Norway spruce (Picea abies), pp. 99-107. In: Rudin, D. (Ed) Proceedings of the IUFRO Conference on Biochemical Genetics of Forest Trees. Umeå, Sweden, 1978.

Bergmann, F. and Kownatzki, D. 1988. The genetic variation pattern of silver fir (Abies $a l b a$ ) in Europe monitored from enzyme gene loci, pp. 21-26. In: Paule, L. and Korpel', S. (Eds) 5. IUFRO-Tannensymposium. VŚLD, Zvolen, ČFSR.

Bergmann, F., Gregorius, H.-R. and Scholz, F. 1989. Isoenzymes, indicators of environmental impacts on plants or environmentally stable gene markers? pp. 17-25. In: Scholz, F., Gregorius, H.-R. and Rudin, D. (Eds) Genetic Effects of Air Pollutants in Forest Tree Populations. Springer-Verlag, Berlin, Heidelberg, New York, Tokyo.

Bergmann, F., Gregorius, II.-R. and Larsen, J. B. 1990. Levels of genetic variation in 
European silver fir (Abies alba) - Are they related to the species decline? Genetica 82: $1-10$.

Bernard-Dagan, C., and Baradat, Ph. 1977. Utilisation des terpènes comme outil en génétique forestière. Proceeding of EEC-Symposium on Forest Tree Biochemistry, Brux. 25-27, January 1977: 109-132.

Bernard-Dagan, C., Fillon, C., Marpeau, A. and Pauly, G. 1982. Les terpènes du Pin maritime: aspects biologiques et génétiques. 2. Hérédité de la teneur en monoterpènes. Ann. Sci. For. 29: 307-334.

Bernard-Dagan, C., Pauly, G., Marpeau, A., Gleizes, M., Carde, J. P. and Baradat, Ph. 1982. Control and compartmentation of terpene biosynthesis in leaves of Pinus pinaster. Physiologie Vegetale 20(4): 775-795.

Birks, J. S. and Kanowski, J. S. 1988. Interpretation of the composition of coniferous resin. Silvae Genetica 37(1): 29-39.

Bonnet-Masimbert, M. and Bikay-Bikay, V. 1978. Variabilité intranspécifique des isozymes de la glutamate-oxaloacetate-transaminase chez Pinus nigra Arnold. Interêt pour la taxonomie des sous especès. Silvae Genetica 27:71-79.

Comps, B., Barrière, G., Merzeau, D. and Letouzey J. 1987. La variabilité alloenzymatique des hêtraies dans les sours-domaines médio- et eu-atlantiques d'Europe. Canad. Journ. For. Res. 17(7): 1043-1049.

Comps, B., Thiebaut, B., Paule, L., Merzeau, D. and Letouzey, J. 1990. Allozyme variability in beechwoods (Fagus sylvatica L.) over central Europe: spatial differentiation among and within populations. Heredity $65: 407-417$.

Comps, B., Thiebaut, B., Sugar, I., Trinajstic, I. and Plazibat, M. 1991. Genetic variability of the croatian beech stands (Fagus sylvatica L.): Spatial differentiation with environment. Ann. des Sci. For. 48:15-28.

Cori, O. M. 1983. Enzymic aspects of the biosynthesis of monoterpenes in plants. Phytochemistry 22: 331-341.

Cuguen. J., Thiebaut, B., N'Tsiba, F. and Barrière, G. 1985. Enzymatic variability of beech stands (Fagus sylvatica L.) on three scales in Europe: evolutionary mechanisms, pp. 1739. In: Jacquart, P., Heim, G. and Antonovics, J. (Eds) Genetic Differentiation and Dispersal in Plants. NATO ASI Series, Springer-Verlag, Berlin, Heidelberg, New York, Tokyo.

Cuguen, J., Merzeau, D. and Thiebaut, B. 1988. Genetic structure of the european beech stands (Fagus sylvatica L.): F-statistics and importance of mating system characteristics in their evolution. Heredity 60:91-100.

Dupoucy, J. L., Fougcrc, V. and Krcmer, A. 1990. Variabilité génćtiquc des chêncs sessile et pédonculé estimée à l'aide de marqueur morphologique moléculaire. Revue Forestière Francaise 42: 198-204.

Esteban, I., Bergmann, F., Gregorius H.-R. and Huhtinen, O. 1976. Composition and Genetics of monoterpenes from cortical oleoresin of Norway spruce and their significance for clone identification. Silvae Genetica 25(2): 59-66.

Fady, B. 1991. Genetic variability of the Greek fir. (submitted to Ann. Sci. For.)

Felber, F. and Thiebaut, B. 1984. Etude préliminaire sur le polymorphisme enzymatique du hêtre, Fagus sylvatica L.: variabilité génétique de deux systèmes de peroxydases en relation avec les conditions écologiques. Acta Oecologica. Oecol. Plant. 5: 133-150.

Fineschi, S. 1984. Determination of the origin of an isolated group of trees of Pinus nigra through enzyme gene markers. Silvae Genetica 33(4-5): 169-172.

Fineschi, S. and Grossoni, P. 1981. Contenuto in monoterpeni di oleoresine xilematiche in provenienze diverse di Pino laricio. Italia forestale montana 36(1): 232-259.

Fineschi, S., Malvolti, E., Morgante, M., Vendramin, G. and Paciucci, M. 1990. Erhaltung von Genressourcen bei der Kastanie (Castanea sativa Mill.), pp. 155-164. In: Hattemer, 
H. H. (Ed) Erhaltung forstlicher Genressourcen. Schriften aus der Forstl. Fak. d. Univ. Göttingen und der Nds. Forstl. Vers. Anst. 98, J.D. Sauerländer's Verlag, Frankfurt a.M.

Forrest, G. I. 1979. Monoterpenic variation in lodgepole pine and Scots pine, pp. 136150. In: Rudin, D. (Ed) Proceedings of the IUFRO Conference on Biochemical Genetics of Forest Trees. Umeả. Sweden 1978.

Forrest, G. I. 1990. Genotypic variation among native Scots pine populations in Scotland based on monoterpene analysis. Forestry 53:101-128.

Gansel, C. E. and Squillace, A. E. 1976. Geographic variation in cortical oleoresin of Slash pine. Silvae Genetica 25(5-6): 150-154.

Gerber, S., Arbez, A., Baradat, Ph. and Marpeau, A. 1991. Geographical variation and terpenic composition of Pinus nigra. (submitted to Silvae Genetica)

Giannini, R., Vendramin, G. and Morgante, M. 1991. Allozyme variation in Italian populations of Picea abies (L.) Karst. Silvae Genetica 40(3-4): 160-166.

Gillet, E. 1990. Probeme der genetischen Analyse von Restriktionsfragment-LängenPolymorphismen (RFLP), pp. 272-277. In: Marker und Genidentifizierung - Methoden und Ergebnisse. Tagungsberichte Arbeitsgemeinschaft Pflanzenzüchtung 8/9. März 1990, Hannover, Vorträge für Pflanzenzüchtung, H. 18.

Gregorius, H.-R. 1978. The concept of genetic diversity and its formal relationship to heterozygosity and genetic distance. Math. Biosci. 41:253-271.

Gregorius, H.-R. 1987. The relationship between the concepts of genetic diversity and differentiation. Theor. Appl. Genet. 74: 397-401.

Gregorius, H.-R. 1988. The meaning of genetic variation within and between subpopulations. Theor. Appl. Genet. 76: 947-951.

Gregorius, H.-R. and Koberds, J. H. 1986. Measurement of genetical differentiation among subpopulations. Theor. Appl. Genet. 71: 826-834.

Gregorius, H.-R., Krauhausen, J. and Müller-Starck, G. 1986. Spatial and temporal genetic differentiation among the seed in a stand of Fagus sylvatica L. Heredity 57:255-262.

Gullberg, U., Yazdani, R. and Rudin, D. 1982. Genetic differentiation between adjacent populations of Pinus sylvestris. Silva Fennica 16(2): 205-214.

Gullberg, U., Yazdani, R., Rudin, D. and Ryman, N. 1985. Allozyme Variation in Scots pine (Pinus sylvestris L.) in Sweden. Silvae Genetica 34(6): 193-201.

Idrissi-Hassani, M. and Lebreton, P. 1992. Les Flavonoïdes du Pin maritime: une approche chimiotaxinomique. Forêt méditerranéenne 13(1):3-8.

Kim, Z. S. 1980. Veränderungen der genetischen Struktur von Buchenpopulationen durch Viabilitätsselektion im Keimlingsstadium, pp. 1-88. Göttingen Res. Notes in Forest Genetics 3 .

Kim, Z. S. 1985. Viability selection at an allozyme locus during development in European beech (Fagus sylvatica L.) Silvae Genetica 34(4-5): 181-186.

Konnert, M. and Franke, F. 1990. Nachkommenschaftsprüfung und Generhaltung von Fichtenbeständen im Schwarzwald, pp. 165-177. In: Hattemer, H. H. (Ed) Erhaltung forstlicher Genressourcen. Schriften aus der Forstl. Fak. d. Univ. Göttingen und der Nds. Forstl. Vers. Anst. J. D. Sauerländer's Verlag, Frankfurt a.M.

Kormuták, A. 1988. Isozyme polymorphism in Slovak populations of silver fir (Abies alba Mill.), pp. 27-39. In: Paule, L. and Korpel', Š. (Eds) 5. IUFRO-Tannensymposium. VŚLD, Zvolen, ČFSR.

Kormuták, A., Benčał, F., Rudin, D. and Seyedyazdani, R. 1982. Isoenzyme variation in the four Slovakian populations of Abies alba Mill. Biológia (Bratislava) 37:433-440.

Krutovskii, K. V., Politov, D. V., Altukhov, Y. P., Milutin, L. I., Kuznetsova, G. V., Iroshnikov, Vorobyev, V. N. and Vorobyeva, N. A. 1989. Genetic variability in Siberian stone pine, Pinus sibirica in Tour. IV. Genetic diversity and amount of genetic differentiation between natural populations. Genetika 25(11): 2009-2032. 
Krutovskii, K. V., Politov, D. V. and Altukhov, Y. P. 1990. Genetic differentiation by isozyme loci between Eurasian cedar pines. Genetika 26(4): 694-707.

Krutovskii, K. V. and Politov, D. V. 1991. Study of intra- and interspecific genetic differentiation of Eurasian cedar pines (Pinus cembra) using isozyme loci and multi-dimensional analysis. In: Molecular Mechanisms of Genetic Processes, Nauka Publishers, Moscow. (in press)

Krzakowa, M. and Szweykowski, J. 1979. Variation of 6-PGD in the populations of Polish Scots pine (Pinus sylvestris), pp. 86-98. In: Rudin, D. (Ed) Proceedings of the Conference on Biochemical Genetics of Forest Trees. Umeå, Sweden 1978.

Krzakowa, M. 1982. Genetic differentiation of Scots pine populations. 1. Genotypes. Silva Fennica 16(2): 200-205.

Lagercrantz, U. and Ryman, N. 1990. Genetic structure of Norway spruce (Picea abies): Concordance of morphological and allozymic variation. Evolution 44:38-53.

Lebreton, P., Laracine-Pittet, C., Bayet, C. and Lauranson, J. 1990. Variabilité des polyphénolique et systématique du Pin sylvestre. Ann. Sci. For. 47: 117-130.

Lewandowski, A. and Mejnartowicz, L. 1992. Levels and patterns of allozyme variation in some European larch (Larix decidua Mill.) populations. Hereditas (in press).

Li, P. and Adams, W. T. 1989. Range - wide patterns of allozyme variation in Douglas-fir. Can. J. For. Res. 19: 149-161.

Loukas, M., Vergini, Y. and Krimbas, C. B. 1983. Isozyme variations and heterozygosity in Pinus halepensis L. Biochemical Genetics 21(5-6): 497-509.

Lumaret, R., Yacine, A., Berrod, A., Romane, F. and T. X. Li. 1991. Mating system and genetic diversity in holm oak (Quercus ilex L., Fagaceae), pp. 149-153. In: Biochemical markers in the population genetics of forest trees. Fineschi, S., Malvolti, M. E., Cannata, F. and Hattemer, H. H. (Eds) SPB Academic Publishing bv, The Hague, The Netherlands.

Lundkvist, K. 1979. Allozyme frequency distributions in four Swedish populations of Norway spruce (Picea abies K.). Hereditas 90: 127-143.

Lundkvist, K. and Rudin, D. 1977. Genetic variation in eleven populations of Picea abies as determined by isozyme analysis. Hereditas 85:67-74.

Marpeau, A. and Baradat, Ph, 1975. Les terpènes du Pin maritime: aspects biologiques et génétiques. 4. Hérédité de la teneur en deux sesquiterpènes: le longifolène le caryophyllène. Ann. Sci. For. 32 (4): 185-204.

Marpeau, A., Baradat, Ph. and Bernard-Dagan, C. 1983. Les terpènes du Pin maritime: aspects biologiques et génétiques. 5. Hérédité de la teneur en limonène. Ann. Sci. For. 40(2): 197216.

Mejnartowicz, L. 1979. Genetic variation in some isoenzyme loci in Scots pine (Pinus silvestris L.) populations. Arboretum Kornickie 24: 91-104.

Mejnartowicz, L. 1980. Polymorphism at the LAP and GOT loci in Abies alba Mill. populations. Bulletin de l'Académie Polonaise des Sciences. Série des Sciences Biologiques. C1. V., 27(12): 1063-1070.

Mejnartowicz, L. and Bergmann, F. 1985. Genetic differentiation among Scots pine populations from the lowlands and the mountains in Poland, pp. 253-266. In: Gregorius, H.-R. (Ed) Population Genetics in Forestry. Lecture Notes in Biomathematics, 60. SpringerVerlag, Berlin, Heidelberg, New York, Tokyo.

Mejnartowicz. L. and Palowski, B. 1989. Studies of Scots pine populations in polluted and clean areas, pp. 115-125. In: Scholz, F., Gregorius, H.-R. and Rudin, D. (Eds) Genetic Effects of Air Pollutants in Forest Tree Populations. Springer-Verlag, Berlin, Heidelberg, New York, Tokyo.

Merzeau, D., Di Giusto, F., Comps, B., Thiebaut, B., Letousey, J. and Cuguen, J. 1989. 
Genetic control of isozyme systems and heterogeneity of pollen contribution in beech (Fagus sylvatica L.). Silvae Genetica 38(5-6): 195-201.

Moreau, M. and Pastuszka P. 1991. Contribution a l'étude de la structure génétique d'un peuplement de sapin pectiné de Basse Vosges. (submitted to Ann. des Sci. For.)

Morgante, M. and Vendramin, G. 1990. Analyse von Genressourcen von Pinus leucodermis Ant., einer Art mit kleinem Verbreitungsgebiet, pp. 87-98. In: Hattemer, H. H. (Ed) Erhaltung forstlicher Genressourcen. Schriften aus der Forstl. Fak. d. Univ. Göttingen und der Nds. Forstl. Vers. Anst. J.D. Sauerländer's Verlag, Frankfurt a.M.

Müller-Starck, G. 1985. Genetic differences between "tolerant" and "sensitive" beeches (Fagus sylvatica L.) in an environmentally stressed adult forest stand. Silvae Genetica 34(6): 241-247.

Müller-Starck, G. 1987. Genetic differentiation among seed samples provenances of Pinus sylvestris L. Silvae Genetica 36(5-6): 232-238.

Müller-Starck, G. 1989. Genetic implications of environmental stress in adult forest stands of Fagus sylvatica L., pp. 127-142. In: Scholz, F, Gregorius, H.-R. and Rudin, D. (Eds) Genetic Effects of Air Pollutants in Forest Tree Populations. Springer-Verlag, Berlin, Heidelberg, New York, Tokyo.

Müller-Starck, G. and Gregorius, H.-R. 1986. Monitoring genetic variation in forest tree populations. Proc. 18th IUFRO World Congress, Ljubljana, Yugoslavia, 1986, Div. 2, Vol. II., 589-599.

Muiller-Starck, G. and Ziehe, M. 1991. Genetic variation in populations of Fagus sylvatica, Quercus robur, and Q. petraea in Germany, pp. 125-140. In: Müller-Starck, G. and Ziehe, M. (Eds) Genetic variation in European Populations of Forest Trees. Sauerländer's Verlag, Frankfurt a.M.

Muona, O. and Szmidt, A. E. 1985. A multilocus study of natural populations of Pinus sylvestris, pp. 226-240. In: Gregorius, H.-R. (Ed) Population Genetics in Forestry. Lecture Notes in Biomathematics, 60. Springer-Verlag, Berlin. Heidelberg, New York, Tokyo.

Muona, O., Paule, L., Szmidt A. E. and Kärkkäinen, V. 1990. Mating system analysis in a central and northern European population of Picea abies. Scand. J. For. Res. 5: 97102.

Nei, M. 1973. Analysis of gene diversity in subdivided populations. Proc. Nat. Acad. Sci. USA 70(12): 3321-3323.

Nikolić, D. and Tucić, N. 1983. Isoenzyme variation within and among populations of european Black pine (Pinus nigra Arnold) Silvae Genetica 32(3-4): 80-89.

Paule L., Yazdani, R. and Gömöry, D. 1987. Monoterpene composition of silver fir foliar oleoresin, pp. 50-66. In: Paule, L. and Korpel', S. (Eds) 5. IUFRO-Tannensymposium. VŠLD, Zvolen, ČFSR.

Pigliucci, M., F. Benedettelli, S. and Villani, 1990. Spatial patterns of genetic variability in Italian chestnut (Castanea sativa Mill.). Can. Journ. Botany. 68: 1962-1968.

Prus-Glowacki, W. and Rudin, D. 1981. Short Note: Studies on antigenic proteins of Pinus sylvestris from six Swedish provenances - A pilot study. Silvae Genetica 30(6): 200203.

Prus-Glowacki, W. 1982. Immunochemical methods in analysis of forest tree proteins. Silva Fennica, Vol. 16(2): 219-226.

Prus-Glowacki, W., Szweykowski, J. J. and Nowak, R. 1985. Serotaxonomical investigation of the European pine species. Silvae Genetica 34(4-5): 162-170.

Rudin, D., Erikson, E., Ekberg, I. and Rasmuson, M. 1974. Studies of allele frequency and inbreeding in Scots pine populations by the aid of the isozyme technique. Silvae Genetica 23(1-3): 10-13. 
Rudloff E. von. 1973. Geographical variation in the terpene composition of the leaf oil of Douglas-fir. Pure Appl. Chem. 34: 401-410.

Schiller, G., Conkle, M. T. and Grunwald, C. 1986. Local differentiation among mediterranean populations of Aleppo pine in their isoenzymes. Silvae Genetica 35(1): 11-19.

Schiller, G. and Grunwald, C. 1987. Resin monoterpenes in range-wide provenance trials of Pinus halepensis in Israel. Silvae Genetica. 36(3-4): 109-114.

Schiller, G. 1990. Variation in resin composition of the Italian cypress (Cupressus sempervirens) grown in Israel. Silvae Genetica 39(3-4): 89-95.

Schröder, S. 1989. Die Weißtanne in Süddeutschland: Genetische Variation, Kline, Korrelationen. Allg. Forst- und Jagdztg., 160: 100-104.

Squillace A. E. 1976. Analysis of monoterpenes of conifers by gas liquid chromatography, pp. 129-157. In: Miksche, J. P. (Ed) Modern methods in Forest Genetics. SpringerVerlag, Heidelberg, Berlin, New York, Tokyo.

Stutz, H. P. 1990. Eigenschaften und Ursachen der genetischen Differenzierung der Fichte im Wallis (Schweiz), pp. 99-114. In: Hattemer, H. H. (Ed) Erhaltung forstlicher Genressourcen. Schriften aus der Forstl. Fak. d. Univ. Göttingen und der Nds. forstl. Vers. Anst. J. D. Sauerländer's Verlag, Frankfurt a.M.

Szmidt, A. 1982. Genetic variation in isolated populations of stone pine (Pinus cembra). Silva Fennica 16(2): 196-200.

Szmidt, A. E., El-Kassaby, Y.-A., Sigurgeirsson, A., Alden, T., Lindgren, D. and Hällgren, J.-E. 1988. Classifying seedlots of Picea sitchensis and P. glauca in zones of introgression using restriction analysis of chloroplast DNA. Theor. Appl. Genetics 76: 841-845.

Szmidt, A. E. 1990. Phylogenetic and applied studies on chloroplast genome in forest conifers. Biochemical markers in the population genetics of forest trees, pp. 185-196. In: Fineschi, S., Malvolti, M. E., Cannata, F. and Hattemer, H. H. (Eds) Biochemical markers in the population genetics of forest trees. SPB Academic Publishing bv, The Hague, The Netherlands.

Thiebaut, B., Lumaret, R. and Vernet, Ph. 1982. The bud enzymes of beech (Fagus sylvatica L.). Genetic distinction and analysis of polymorphism in several french populations. Silvae Genetica 31(2-3): 51-60.

Thielges, B. A. 1972. Intraspecific variation in foliage polyphenole of Pinus (subsection sylvestris). Silvae Genetica 21(3-4): 114-119.

Tigerstedt, P. M. A. 1973. Studies on isozymc variation in marginal and central populations of Picea abies. Hereditas 75:47-60.

Tigerstedt, P. M. A. 1979. Genetic adaptation of plants in the subartic environment. Holarctic Ecology 2: 264-268.

Tigerstedt P. M. A., Hiltunen, R., Chung, M. S. and Moren, E. 1979. Inheritance and genetic variation of monoterpenes in Pinus sylvestris, pp. 29-39. In: Rudin, E. (Ed) Proceedings of the IUFRO Conference on Biochemical Genetics of Forest Trees, Umeå, Sweden 1978.

Valizadeh, M. 1977. Esterase and acid phosphatase polimorphism in the fig tree (Ficus carica L.) Biochemical Genetics 15: 1037-1048.

Villani, F., Benedettelli, S., Paciucci, M., Cherubini, M. and Pigliucci, M. 1991a. Genetic variation and differentiation between natural populations of chestnut (Castanea sativa Mill.) from Italy, pp. 91-103. In: Fineschi, S., Malvolti, M. E., Cannata, F. and Hattemer, H. H. (Eds) Biochemical markers in the population genetics of forest trees. SPB Academic Publishing bv, The Hague, The Netherlands.

Villani, F., Pugliucci, M., Benedettelli, S. and Cherubini, M. 1991b. Genetic vs. geographical and climatic differentiation of Turkish chestnut. (Castanea sativa Mill.) Heredity 66: $131-136$. 
Wellendorf H. and Kaufmann, U. 1977. This layer chromatography of fluorescent phenolic compounds in needles: A review of current activities in Picea, pp. 203-226. In: Proceedings of EEC Symposium on Forest Tree Biochemistry, Bruxelles, Belgium.

White, E. C. and Nilsson, J. E. 1984. Genetic variation in resin canal frequency and relationships to terpene production in foliage of Pinus contorta. Silvae Genetica 33(23): $79-84$.

Wright, S. 1943. Isolation of distance. Genetics 28: 114-138.

Wright, S. 1951. The genetic structure of populations. Ann. Eugenics 15: 323-354.

Wright, S. 1969. Evolution and the Genetics of Populations. Vol. 2. The Theory of Gene Frequencies. Univ. of Chicago Press, Chicago.

Yazdani R. and Lebreton, P. 1991. Inheritance pattern of the flavonic compounds in Scots pine. Silvae Genetica 40(2): 57-59.

Yazdani, R., Nilsson, J. E. and Ericsson, T. 1985. Geographical variation in the relative proportion and monoterpenes in cortical oleorosis of Pinus sylvestris in Sweden. Silvae Genetica 34(6): 201-208.

Yazdani, R. and Nilsson, J. E. 1986. Cortical monoterpene variation in natural populations of Pinus sylvestris in Sweden, Scand. J. For. Res. 1: 85-93.

Yazdani, R., Rudin, R., Aldén, T., Lindgren, L., Harbom, B. and Ljung, K. 1982. Inheritance pattern of five monoterpenes in Scots pine. Hereditas 97:261-272.

Zanetto, A. and Kremer A. 1991. Allozyme polymorphism of sessile oak populations in western Europe. (submitted to Ann. Sci. For.)

Zavarin E. 1970. Qualitative and quantitative co-occurence of terpenoids as a tool of elucidation to their biosynthesis. Phytochemistry 9: 1049-1963. 